\title{
Representação e virtualidade em videogames
}

\section{Rune Klevjer}

Doutor; University of Bergen, Bergen, Noruega

rune.klevjer@uib.no

Tradução: Deni E. Silva

Universidade Federal do Rio Grande do Sul, Porto Alegre, RS, Brasil denijuniorr@gmail.com

\section{Suely Fragoso}

Universidade Federal do Rio Grande do Sul, Porto Alegre, RS, Brasil suelyfragoso@ufrgs.br

Revisão de tradução: Fabiana Freitas

Universidade Federal do Rio Grande do Sul, Porto Alegre, RS, Brasil frrfreitas@gmail.com

\section{Resumo}

$\mathrm{O}$ artigo discute a natureza dos ambientes gráficos participativos em tempo real, que correspondem à configuração que viabiliza uma ampla variedade de gêneros de games de ação. Ao adotar uma definição positiva de virtualidade, argumento que a noção de virtual dá conta do status ontológico desses ambientes. Inicio o argumento apresentando como a oposição entre ação e representação leva o conceito de virtualidade a um beco sem saída para, a seguir, explorar outras abordagens possíveis. Essa exploração culmina na conclusão de que, diferentemente dos modelos abstratos e concretos do jogar mimético nãocomputadorizado, a simulação da realidade física nos games é capaz de constituir seu próprio e irredutível terreno de percepção e ação. Quando avaliados desde um ponto de vista objetivo e externo, os modelos espaço-visuais gráficos dos jogos de computador são modelos de segunda-ordem. Entretanto, em uma perspectiva fenomenológica, o sujeito é capaz de, de fato verdade obrigado a se engajar com eles como se fossem modelos de primeira-ordem, como se fossem objetos e ambientes concretos, não informacionais. Do ponto de vista do participante, a participação em simulações gráficas em tempo real não apenas simula, mas cria, uma ontologia separada. 


\section{Palavras-chave}

Videogame. Estudos de Jogos. Representação. Ambiente Virtual. Tempo-Real.

Neste artigo eu quero discutir a natureza de ambientes gráficos participativos em tempo-real, configuração que torna possível uma grande variedade de gêneros de jogos de ação, de SpaceWar! (1962) até os jogos 3D de ação/aventura contemporâneos, inclusive os do gênero tiro em primeira pessoa $\left(F P S^{1}\right)$. É claro que os gráficos em tempo-real também existem fora do campo dos videogames, sendo encontrados em muitos lugares, desde softwares de computação gráfica até aplicações em realidade virtual (VR) totalmente imersivas. Porém, eu diria que são primariamente associados com os videogames e a sua cultura. No senso comum e no ambiente acadêmico, a categoria geral "videogames" é às vezes usada - mesmo que incorretamente - como sinônimo de "jogos com gráficos em tempo-real".

Proponho que ambientes gráficos em tempo-real são melhor compreendidos como uma simulação de um mundo físico quando o engajamento com eles ocorre da forma intuitiva e que já se tornou habitual nos jogos. Essa compreensão é compatível com a noção de virtual. Em resposta a John Richard Sageng (2012), para quem essa noção seria uma categoria intermediária vazia e um beco-sem-saída filosófico (uma rota de fuga para um fenômeno que parece desconfortavelmente situado entre o real e o ficcional), sugiro uma definição positiva de virtualidade que deveria ser conceitualizada como uma categoria ontológica irredutível.

Comecemos assumindo que ambientes gráficos em tempo-real, do tipo que me interessa neste artigo, pertencem à categoria mais ampla de simulações. Em uma definição abrangente, uma simulação é a implementação de um modelo e, de acordo com Umberto Eco (1976, 209), um modelo é uma "representação funcional" que reproduz algum aspecto funcional daquilo que modela. Uma vassoura, por exemplo, pode ser usada como um modelo na medida em que é capaz de reproduzir algum aspecto funcional de um cavalo ou uma criatura similar. Em uma categorização preliminar, um modelo pode ser concreto (um soldadinho de lata, um boneco de testes de colisão ou abstrato (um modelo climático, um algoritmo de renderização). Jogos miméticos como War ou xadrez também são baseados em

${ }^{1}$ Nota dos tradutores: Jogos desse tipo são muitas vezes referidos apenas por esse acrônimo do inglês "First Person Shooter". 
modelos que são implementados como simulações durante o jogo, ainda que esse aspecto nem sempre seja uma parte significativa da experiência.

Em termos de seu status de realidade, simulações de jogos, especialmente simulações de jogos de computador, parecem pertencer a algum lugar entre a realidade no sentido cotidiano (fora da simulação) e ficções no sentido tradicional: estórias, romances, filmes. Espen Aarseth usa "virtual" e "simulado" como sinônimos:

Resumindo, jogos não são ficções, mas um tipo de mundo diferente, entre a ficção e o nosso mundo: o virtual. Há também outros mundos: mundos de sonhos, experimentos mentais, percepções religiosas, mundos espelhados ${ }^{2}$, etc. Todos esses são mundos alternativos ao nosso, tão diferentes de ficção quanto uns dos outros (AARSETH, 2007, p.39).

Parece claro que os mundos simulados dos jogos de computador são diferentes de ficções, pelo menos no sentido em que a noção de "ficção" é comumente entendida: como mundos e eventos que são projetados em nossas imaginações. Entretanto, devemos observar que Aarseth não distingue entre simulações geradas em computador e outras simulações; para ele, mundos de jogos de computador não são "virtuais" porque são computadorizados, mas porque são simulações. Ainda que sua observação seja similar em outros aspectos, Philip Brey (2003) define virtualidade especificamente como um resultado das capacidades do computador digital:

À primeira vista, o status ontológico de entidades virtuais é intrigante. Elas se assemelham a objetos fictícios como personagens em livros ou filmes porque não possuem existência física: elas não têm massa ou localização identificável no espaço físico. Entretanto, entidades virtuais não são apenas objetos ficcionais, porque elas frequentemente têm características perceptivas ricas e, mais importante, elas são interativas: elas podem ser manipuladas, respondem às nossas ações, e podem estabelecer relações causais com outras entidades. Então, em nossa ontologia cotidiana, entidades virtuais parecem ocupar um lugar especial: são diferentes de entidades físicas, mas também diferentes de entidades fictícias ou imaginárias. (BREY, 2003).

Embora Brey (2003) enfatize que entidades virtuais desse tipo particular pertencem à categoria de simulação3 ${ }^{3}$ ele não está preocupado com a natureza de simulações como tal. 0 que lhe interessa é o modo como o computador, diferentemente de qualquer outra

\footnotetext{
2 Nota dos tradutores: a expressão em inglês "mirror worlds" é utilizada em referência a reproduções digitais do mundo físico.

${ }^{3}$ Brey opõe a categoria de simulações virtuais a "reproduções" virtuais como dinheiro, documentos ou cor - entidades que possuem diretamente o mesmo status de realidade em sua forma computadorizada como em qualquer outra.
} 
tecnologia, é capaz de simular realidade física, gerando objetos que não são entidades físicas (sem massa, sem localização), mas que se comportam como se o fossem. É essa fisicalidade simulada que concede às entidades virtuais um "lugar especial" em nossa "ontologia cotidiana", não apenas o simples fato de serem entidades simuladas.

Porém, mesmo se aceitarmos, em termos gerais, que a capacidade de simular ambientes físicos é fundamental para o status de "terceiro lugar" dos mundos de jogos de computador em relação a ficções e à realidade comum, como acredito que deveríamos, permanece em aberto a difícil questão da representação em ambientes gráficos em tempo real: quando interagimos com exemplares "quase físicos" de escadas, armas, água ou quaisquer coisa, de maneiras que intuitivamente assemelham-se a alguns aspectos importantes de como interagiríamos com os objetos e elementos correspondentes na vida real, isso implica que nossas interações também são meras representações de ações ao invés de ações reais, do mesmo modo que, presumivelmente, água simulada por computador é uma representação de água real?

Em seu artigo In-Game Action (2012), John Richard Sageng discute esse problema, e propõe uma solução. 0 coração do problema, ele argumenta, é que ação e representação são categorias mutuamente incompatíveis; elas articulam "direções de ajuste" opostas na relação entre o sujeito e o mundo ${ }^{2}$. Representações são direcionadas a afetar nossas percepções e entendimentos sobre o mundo, o que significa que elas têm uma direção de ajuste da-mente-para-o-mundo (SAGENG, 2012, p.7). Em contraste, ações têm uma direção de ajuste do-mundo-para-a-mente:

Ação é também um conceito que relaciona um sujeito ao mundo, mas a noção está ligada a um conjunto diferente de componentes envolvidos no sucesso de uma direção de ajuste oposta. 0 conceito de uma ação está ligado à função de designar o local apropriado de um sujeito autônomo na ordem causal de acontecimentos. Carros param, corpos se movem, vidros quebram, mas o que faz com que alguns desses acontecimentos sejam ações e outros não é a participação ativa de um sujeito que ajusta o mundo aos seus desejos (SAGENG, 2012, p. 7).

Desse modo, parece que não se pode ter as duas coisas. Qualquer ato - digamos, beber um copo de água - deve ser avaliado baseado na sua intenção de representar algo, em outras palavras como algo que podemos chamar de um ato mimético, ou deve ser considerado uma ação no sentido acima, que, nesse caso, seria presumivelmente destinada a matar a sede. $\mathrm{Ou}$ 
você está causalmente motivado, e faz algo, ou representa algo. Ou você mata alguém, ou finge matar alguém.

A respeito da ação em ambientes de jogos de computador, portanto, a solução de Sageng é que devemos considerar separadamente os dois tipos diferentes de atos que ocorrem ao mesmo tempo: a ação causalmente motivada, $e$ o ato de representação. Para qualificar como ação de fato, o primeiro não pode ser direcionado para armas ou escadas, deve ser causalmente direcionado para algo que esteja realmente na tela - que é uma corrente de "acontecimentos gráficos não-representativos" (SAGENG, 2012, p.20). Os atos representativos devem ser entendidos como um contexto especializado, uma interpretação de eventos, espelhando as ações reais do jogador em alguns aspectos relevantes. Então mesmo que interpretemos ações na tela em termos representativos, o que frequentemente é inevitável, a ação só pode ir adiante através de uma "mudança de referência" dos eventos miméticos para os objetos reais no jogo, as formas na tela. Consequentemente, atos representativos em jogos de computador são uma dimensão "opcional", (SAGENG, 2012, p.20), pegando carona em ações que são diretamente reais. 0 jogador está literalmente manipulando formas dinâmicas na tela, enquanto, ao mesmo tempo, tem a opção de fingir que está atirando em inimigos com uma arma.

Uma vez que a incompatibilidade categórica de ação e representação está estabelecida com base em suas direções de ajuste opostas, Sageng aponta que não há uso para noções de simulação ou "virtualidade", do tipo proposto por Aarseth ou Brey. Simulação não implica que representação acontece através da ação - mas isso não resolve o problema de Sageng, uma vez que apenas afirma que essa dupla articulação é possível, mas não resolve o dilema das ações versus ações simuladas.

De fato, a tensão contida na questão da virtualidade foi abordada de forma bem abrangente - embora do ponto de vista da história cultural - por Roger Cailois em seu clássico Man, Play and Games (2001). Nele, o autor explica como e porque jogos de faz-deconta e jogos competitivos baseados em regras não se misturam bem. Considerações teóricas e evidências empíricas mostram que qualquer atividade de jogo irá se enquadrar em uma ou outra categoria: como mimesis ou como agon. Uma partida de futebol em que os jogadores vistam fantasias engraçadas, por exemplo, ou não seria realmente sobre as fantasias ou, como mais comumente seria o caso, não seria realmente sobre vencer. Nos termos de Sageng, poderíamos dizer que um desses atos, a ação ou a representação, teria que ficar em segundo plano, como uma espécie de comentário paralelo. 
A tese da incompatibilidade parece inevitável quando consideramos uma variedade de atividades miméticas não computadorizadas, que, para os propósitos deste trabalho, vou dividir em duas categorias: encenações (atuação, performance, role-playing, vários tipos de práticas ritualísticas) e jogos miméticos, como Banco Imobiliário ou paintball. Enquanto o primeiro tipo de atividade é definido por atos de fazer de conta (motivações, objetivos e efeitos "encenados"), o segundo tipo é definido através de ações reais, que podem opcionalmente ser interpretadas ou tematizadas através de contextos de faz-de-conta de várias maneiras - como extensamente analisado por Juul (2005), Salen e Zimmerman (2012) e Järvinen (2009), entre outros. Na terminologia de Torben Gragh Grodal, diríamos que enquanto encenações, como estórias e filmes, oferecem aos seus participantes experiências indiretas, ou de segunda mão, os jogos oferecem experiências em primeira mão (Grodal, 2003). Enquanto encenações usam adereços como ferramentas de expressão, jogos miméticos usam modelos como facilitadores de ações e simulações.

A noção de enquadramento, ou framing, conforme introduzida por Gregory Bateson e desenvolvida por Erwin Goffman (2012), é útil para explicar o status opcional dos eventos representativos em jogos miméticos ou em outros tipos de atividades baseadas em modelos.

Em uma explicação superficial, um "frame" é uma convenção social que rege a compreensão mútua das pessoas sobre uma específica situação social. As interações das pessoas em uma festa, por exemplo, serão enquadradas por um conjunto de convenções mais ou menos padronizadas sobre como se comportar em festas daquele tipo, e esse enquadramento permite que os participantes se orientem e estejam razoavelmente em sintonia com os outros sobre como se comportar, sobre o significado das coisas, e em geral, sobre "o que é que está acontecendo" (Goffman, 2012). 0 limite de um dado enquadramento pode ser padronizado ou em fluxo, fixo ou instável. Mais importante para o nosso contexto: os significados das interações sociais são frequentemente regidos por um composto de frames, no qual um frame pode operar como sobreposição ou "laminação" de outro frame, agindo como um modificador que muda o sentido original do que está acontecendo. Uma sobreposição típica e cotidiana, por exemplo, seria a adição de um frame de "brincadeira", que transforma uma grande variedade de interações e sentidos, como agressão e surpresa, em diversão amigável. 0 ato de adicionar tal frame de "laminação", através de linguagem ou ações, é o que chamado de "elevar o tom4" por Goffman (2012).

\footnotetext{
${ }^{4}$ Nota dos tradutores: no original, up-keying. 0 termo keying, de difícil tradução para o português, remete, em linhas gerais, à ideia de transformação sistemática, dentre outras características.
} 
Em jogos miméticos, o chaveamento de um quadro sobreposto acontece através da implementação de modelos. 0 sistema de regras formais articula um modelo abstrato unificador, que pode definir, por exemplo, que peões só podem se mover para frente no tabuleiro, e que o jogo acaba quando a peça "Rei" é tomada. Quando (ou se) tomado como modelo abstrato, pode-se interpretar como camponeses não tendo permissão para recuar no campo de batalha, e que a batalha acaba quando o rei é capturado. No xadrez, também há modelos concretos, o tabuleiro e as peças, cuja aparência e, em certa medida, as características físicas básicas (como tamanho) ajudam a articular certos sentidos e estruturas de ações. Obviamente, o mundo de campos de batalha, reis e camponeses pode ser "descascado", por assim dizer. Isso corresponderia ao que Goffman (2012) chama de "rebaixar o tom", que consiste em remover as laminações do frame sobreposto.

A conceitualização de jogos miméticos como uma questão de enquadramentos me parece ressoar bem com a consideração de Sageng (2012) sobre ação no ambiente de jogo, embora ele sugira a noção de "mudança de referência" ao invés de enquadramentos e chaveamentos como a solução para o problema ação-representação.

Podemos identificar nesse contexto que as imagens figurativas, ou pelo menos uma grande parte delas, não seguem esse paradigma, pois não se pode afirmar que no caso delas a produção de significado dependa de "elevar o tom". Desde que intuitivamente e inevitavelmente reconhecíveis ao nível da percepção, um retrato ou uma animação o possuem um status padrão enquanto representações, no quadro primário; não é possível "rebaixar o tom" delas como em eventos representativos sobrepostos. Pode-se tentar quebrar ou "descascar" o conteúdo representativo do ato supostamente real de olhar para a pintura, mas essa estratégia exigiria que consideremos o ato de olhar para a pintura meramente como uma superfície enquadrada e estruturada, independentemente de reconhecer suas características representativas, como uma "ação" no sentido próprio e intencional. Porém, ao meu ver, esse tipo de "olhar" seria uma abstração, um frame secundário que estaria sendo adicionado à ação padrão de olhar para a pintura, que é um ato perceptivo que implica o reconhecimento das características representativas. Concluo, portanto, que representações visuais sempre operam no quadro primário; não há quadro de ação significativo do qual elas possam sofrer "rebaixamento de tom".

Em contraste, atividades miméticas sempre são fundamentadas, no sentido de que o frame representativo é sobreposto a um frame primário e não mimético de interação, para o qual o tom da atividade pode ser "rebaixado"; encenações podem ter seu tom "rebaixado" 
para a atuação que está acontecendo, e jogos miméticos podem ter seu tom "rebaixado" para o jogar que está acontecendo.

O mesmo modelo parece servir aos jogos de computador: o jogador joga com formas gráficas na tela, através de botões e de bastões analógicos, de modo que a estrutura das ações e a dinâmica visual são capazes de, persuasivamente, "elevar o tom" das ações reais do jogador para um frame de eventos miméticos, sobrepostos ao domínio da ação real.

Entretanto, vamos voltar à descrição de virtualidade de Philip Brey (2003). Ele não conceitua as ações do usuário como dirigidas às formas na tela, mas às entidades simuladas pelo computador. A questão, então, é se o último tipo de consideração exclui o primeiro. A possibilidade de ação em ambientes gráficos implica que objetos na tela sejam "sempre já" percebidos como objetos físicos simulados? Se esse for o caso, então o problema da açãorepresentação será, em um sentido importante, insolúvel. Só podemos resolver essa questão se pudermos distinguir entre dois níveis diferentes de eventos, de modo que, ao nível de simulação de Brey (2003) (ação direcionada a entidades simuladas), seja negado o status de ação propriamente dita.

Em jogos miméticos não computadorizados, essa não é uma tarefa difícil, pois as atividades sempre vão ter um fundamento sólido. Quando removemos a camada representativa, o espaço físico natural do corpo garante que há um frame de interação primário e não representativo no qual se apoiar, empírica e filosoficamente; movemos as peças com as nossas mãos, corremos no bosque, movemos nossos corpos para nos expressarmos. De fato, não é controverso dizer que a possibilidade de ação é parte da definição do que é o espaço natural corporificado.

O que me traz ao meu interesse central: em jogos de computador, não é claro como nossa interação com ambientes gráficos em tempo real possui uma fundamentação similar no espaço natural corporificado, independentemente da nossa percepção e manipulação de objetos simulados. Isso pode ser verdadeiro para alguns jogos (Tetris?), mas parece mais duvidoso no caso de jogos baseados em ambientes simulados em tempo real, por exemplo jogos de corrida. Se existisse um frame no qual pudéssemos assegurar a independência das ações, ou o domínio intencional do objeto teria que ser a própria interface física (controles, bastões analógicos, botões), ou deveria haver um conjunto de padrões audiovisuais não representativos mas jogáveis, reconhecíveis na tela em frente ao jogador. Vou considerar este problema e uma noção fenomenológica de intencionalidade perceptiva, antes de retornar às considerações de Sageng (2012). 
O argumento fenomenológico básico que quero empregar aqui, retirado da obra Fenomenologia da Percepção (2018), de Maurice Merleau-Ponty, é que nossas ações e percepções são necessariamente articuladas em termos de sua intencionalidade. Quando pegamos algo com nossas mãos, o que se qualifica como ação é o pegar do objeto, não o movimento do braço. E o que se qualifica como percepção não é perceber o movimento do braço, mas perceber o pegar o objeto. Portanto, em um Jogo de Tiro em Primeira Pessoa (FPS), o que vemos é um espaço tridimensional, não a superfície bidimensional de sua projeção. Nossa intenção, no sentido perceptivo e no sentido comum do termo, não é direcionada ao movimento dos bastões analógicos do controle, mas ao movimento de nosso ponto de vista subjetivo no espaço tridimensional.

Como argumentei em outro lugar (Klevjer, 2012), a interface padrão que surgiu com os gêneros de ação-aventura de jogos de computador - mouse e teclado ou botões e bastões analógicos - exige, como um imperativo absoluto, que a interface de hardware seja incorporada como uma extensão prostética do próprio corpo fenomenológico do jogador, portanto não se qualificando mais como um objeto intencional na percepção. Em ambientes 3D navegáveis, essas extensões corporais incorporadas também incluem, tipicamente, não apenas a interface de hardware, mas também a marionete e/ou veículo controlável na tela, assim como, de forma mais importante, a própria câmera navegável, na medida em que ela é diretamente controlável.

Uma exceção ilustrativa desse modelo seriam as ações de um jogador incompetente e malsucedido. Jogos de computador devem ser aprendidos e, por isso, um jogador que seja totalmente estranho à interface básica de interação irá direcionar suas ações à própria interface física, e não conseguirá ter sucesso em nenhuma ação direcionada além desta interface; botões serão pressionados e bastões movidos, e isso seria de fato qualificado como uma ação própria, em qualquer abordagem.

Entretanto, na medida em que jogadores capazes de se engajar com sucesso além desse nível, na maneira intuitiva exigida pelas interfaces padrão dos consoles ou computadores, a percepção e a ação não são mais articuladas em termos da relação do jogador com botões, bastões e tela, ou seja: não mais direcionada aos objetos no espaço corporal natural. A natureza protética do engajamento bem-sucedido com ambientes gráficos em tempo real implica que, na medida em que nossas percepções e ações são intuitivamente direcionadas e ancoradas em outro lugar, nosso frame padrão de ação 
corpórea natural - nosso espaço fenomenológico como sentados em frente a uma tela - será suspenso perceptivamente.

De fato, é precisamente assim que jogos casuais controlados por movimentos em consoles (Wii, Kinect, PlayStation Move) claramente se diferenciam do paradigma padrão; como Jesper Juul (2010) aponta, essas interfaces articulam um espaço de jogo aqui, na frente da tela, ao invés de "lá", no espaço simulado por computador.

A consideração de Sageng sobre ações "in-game" compartilha a premissa geral de que uma ação deve ser intencional para se qualificar como agência: "O sujeito, tendo certas necessidades ou desejos, forma uma intenção, e deliberadamente obtém o resultado pretendido por meio de movimentos de seu corpo" (SAGENG, 2012, p.8). A diferença central entre essa consideração e a minha própria posição parece estar relacionada à noção de percepção, embora não de maneira explícita:

(...) o efeito de introduzir ação é que o objeto intencional dos jogadores muda dos acontecimentos fictícios representados originalmente para as coisas com as quais ele interage, que são simplesmente as formas gráficas espaço-visuais que ele vê na tela (SAGENG, 2012, p.17)

O problema reside em discernir em que medida podemos dizer que o jogador realmente percebe "formas gráficas espaço-visuais" durante o jogo. É verdade que ele estará agindo de modo a afetar e responder aos comportamentos de tais formas na superfície da tela (assim como aos sons vindos dos alto-falantes, devemos acrescentar). Porém, o ponto delicado é se o jogador "vê diante de si na tela" uma série de formas gráficas não representativas, em relação às quais é capaz de configurar uma intenção, conscientemente ou intuitivamente. No modo padrão de engajamento competitivo que descrevi acima, não vejo como isso seria possível, sendo especialmente difícil de entender no caso de ambientes tridimensionais, que não apenas simulam a massa, solidez e causalidade física, mas também espacialidade e posicionamento - que são projetados como formas gráficas desenhadas em uma superfície plana, mas dificilmente inteligíveis para o jogador dessa forma.

Sugiro, então, que a melhor "solução" para nosso problema seja aceitar que, ao contrário do que ocorre com modelos concretos e abstratos de jogos miméticos não computadorizados, a simulação da realidade física em jogos de computador é capaz de constituir sua própria e irredutível base de percepção e ação. As ações do jogador não possuem um fundamento independente dentro dos parâmetros fenomenológicos do espaço naturalmente corporificado, mas devem ser direcionadas para objetos e eventos no espaço 
virtual. Como imagens, nossas interações com objetos virtuais operam necessariamente no quadro primário, não havendo quadro de ação significativo no qual seja possível "rebaixar o tom" delas.

Esse é claramente um problema filosófico. A regra de "direção de ajuste" é aparentemente quebrada; nenhum "rebaixamento de tom" ou "mudança de referência" é possível, o que poderia ter nos direcionado a um domínio sem simulação sob os eventos simulados. Em outras palavras, só nos resta aceitar: a tecnologia do computador gerou um espaço realmente paradoxal para interação e expressão, no qual ação e ação simulada não podem ser separadas. Para finalizar, tentarei esboçar uma breve descrição positiva de objetos virtuais e espaço virtual.

O que distingue ambientes gráficos em tempo real de tabuleiros de jogos, de armas de brinquedo e, ainda, de sistemas de regras formais de jogos, é que eles são modelos abstratos - modelos algorítmicos - que são percebidos e manipulados como modelos concretos. "Concreto" não significa apenas que nós somos capazes de interagir com eles, mas, mais particularmente, que podemos tocá-los. 0 computador digital possui a capacidade única de transformar modelos algorítmicos em objetos de interação tangível. Na análise clássica de David Sudnow's sobre jogos de videogame, Pilgrim in the Microworld, de 1983:

Existe o espaço de lá e este espaço aqui, e nós atravessamos o vão estaiado com movimentos que, todavia, nos fazem sentir como se estivéssemos em prolongado e estendido contato com as coisas (SUDNOW, 1983)

De certo modo, portanto, podemos dizer que o espaço virtual é espaço encantado. Em jogos de computador em tempo real, quando avaliados por um ponto de vista externo objetivo, modelos gráficos espaço-visuais são modelos de segunda ordem (modelos de modelos). Entretanto, na perspectiva fenomenológica, o sujeito pode, e na verdade deve, engajar-se com eles como se fossem modelos de primeira ordem, como se fossem objetos e ambientes concretos ao invés de informacionais. Então, os modelos abstratos dos programadores foram, de certo modo, reificados. Informação é transformada em natureza. Em um contexto histórico e cultural mais amplo, tais objetos programados reificados talvez não sejam tão diferentes de montanhas encantadas ou autômatos Vitorianos.

A questão do status ontológico exato do espaço virtual, entendido como programado mas reificado e como espaço fenomenológico não-irredutível, deve permanecer. Talvez possamos dizer que, do ponto de vista do participante, simulações gráficas participativas em 
tempo real não apenas simulam uma ontologia separada, mas criam uma. Em qualquer caso, os parâmetros de interação corporal são diferentes, e a relação entre ação e representação que havíamos naturalizado é reformulada. Então acredito que, em termos amplos, Philip Brey está correto quando sugere que ambientes físicos simulados por computador são "talvez menos uma extensão de nós mesmos do que uma extensão de nosso mundo" (Brey 2005, 395). Um comprometimento filosófico com a natureza intencional da ação e percepção nos leva a concluir que os mundos gerados por computador de SapceWar! e Grand Theft Auto V (2013) não são, como se poderia assumir, frames de ação sobrepostos, mas espaços corpóreos separados e alternativos, com os quais nos envolvemos como uma segunda natureza. "Realidade virtual" é um termo adequado aqui, mesmo quando mediada através de uma superfície enquadrada.

\section{Referências}

AARSETH, Espen. Doors and Perception: Fiction vs. Simulation in Games. History And Theory Of The Arts, Literature And Technologies, [s.l], n. 9, p.35-44, 2007.

ANSCOMBE, Elizabeth. Intention. Oxford: Basil Blackwell, 1957.

BREY, Philip. The Social Ontology of Virtual Environments. American Journal of Economics And Sociology, [s.l], v. 1, n. 62, p.269-282, 2003.

BREY, Philip. The Epistemology and Ontology of Human-Computer Interaction. Minds And Machines, [s.l], n. 15, p.383-398, 2005.

CAILLOIS, Roger. Os jogos e os homens: a máscara e a vertigem. Rio de Janeiro: Vozes, 2017.

ECO, Umberto. A Theory of Semiotics. Bloomington: Indiana University Press, 1976.

GOFFMAN, Erving. Quadros da experiência social: Uma perspectiva de análise. Rio de Janeiro: Vozes, 2012.

GRODAL, Torben. Stories for Eye, Ear, and Muscles: Video Games, Media, and Embodied experiences. In: WOLF, Mark J. P.; PERRON, Bernard (Ed.). The Video Game Theory Reader. Londres: Routledge, 2003. p. 129-155.

JUUL, Jesper. Half-Real: Video Games between Real Rules and Fictional Worlds. Cambridge, Massachusetts: MIT Press, 2005. 
JUUL, Jesper. A casual revolution: reinventing video games and their players. Cambridge, Mass.: MIT Press., 2010

JÄRVINEN, Aki. Games without Frontiers: Methods for Game Studies and Design. Saarbrücken: VDM Verlag. 2009.

KLEVJER, Rune. Enter the Avatar: The phenomenology of prosthetic telepresence in computer games. In: FOSSHEIM, Hallvard; LARSEN, Tarjei Mandt; SAGENG, John Richard (Org.). The Philosophy of Computer Games. Londres, Nova York: Springer, 2012. p. 17-38.

MERLEAU-PONTY, Maurice. Fenomenologia da Percepção. São Paulo: Martins Fontes, 2018.

SAGENG, John Richard. In-Game Action. In: FOSSHEIM, Hallvard; LARSEN, Tarjei Mandt; SAGENG, John Richard (Org.). The Philosophy of Computer Games. Londres, Nova York: Springer, 2012. p. 219-232.

SALEN, Katie e ZIMMERMAN, Eric. Regras do jogo: Fundamentos do Game Design. São Paulo: Blucher, 2012.

SUDNOW, David. Pilgrim in the Microworld: Eye, Mind and the Essence of Video Skill. New York: Warner Books, 1983.

\title{
Representation and virtuality in computer games
}

\begin{abstract}
In this article, I discuss the nature of participatory real-time graphical environments, which is the general form that enables a wide range of genres of action games. By adopting a positive definition of virtuality, I argue that the notion of virtual aptly accounts for the ontological status of these environments. I begin the argument by presenting how the opposition between action and representation leads the concept of virtuality to a dead end and proceed to explore other possible approaches. This exploration culminates in the conclusion that, unlike the abstract and concrete models of non-computerized mimetic play, the simulation of physical reality in games is capable of constituting its own irreducible ground of perception and action. When evaluated from an objective outside view, the spatiovisual graphical models of computer games are second-order models. However, from the phenomenal perspective, the subject is able to, and indeed required to, engage with them as first-order models, as if they were concrete objects and environments, not informational ones. From the participant's point of view, real-time participatory graphical simulations not only simulate a separate ontology, but creates it.
\end{abstract}




\section{Keywords}

Spatio-visual graphical models. Ontology. Virtual. 